\title{
CHRONIC OBSTRUCTIVE PULMONARY DISEASE
}

\section{Correlation between change in pulmonary function and suppression of reactive nitrogen species production following steroid treatment in COPD}

\author{
H Sugiura, M Ichinose, S Yamagata, A Koarai, K Shirato, T Hattori
}

Thorax 2003;58:299-305

See end of article for authors' affiliations

Correspondence to: DrM lchinose, Division of Respiratory and Infectious

Diseases, Tohoku University

Graduate School of

Medicine, 1-1

Seiryo-machi, Aoba-ku,

Sendai, 980-8574, Japan;

ichinose@

intl.med.tohoku.ac.jp

Revised version received 7 December 2002

Accepted for publication

11 December 2002

\begin{abstract}
Background: Reactive nitrogen species (RNS) have a number of inflammatory actions and the production of these molecules has been reported to be increased in the airways of patients with chronic obstructive pulmonary disease (COPD), which suggests that they may be involved in the inflammatory and obstructive process in COPD.

Methods: The relationship between the reduction in RNS and the improvement in pulmonary function was studied in 18 patients with COPD following steroid treatment $(800 \mu \mathrm{g}$ beclomethasone dipropionate inhalation for 4 weeks). Twelve patients were treated with inhaled steroids and the others received placebo treatment. Forced expiratory volume in 1 second $\left(F E V_{1}\right)$ and airway responsiveness to histamine were measured before and after treatment. Induced sputum cells were stained with anti-nitrotyrosine antibody, a footprint of RNS, and RNS formation was assessed by measuring nitrotyrosine immunoreactivity. The immunoreactivity of inducible nitric oxide synthase (iNOS) in induced sputum and exhaled NO levels were also measured.

Results: Treatment with steroids resulted in a significant reduction in both nitrotyrosine and iNOS immunoreactivity in sputum cells compared with pretreatment levels (both $p<0.01$ ). The reduction rates in both parameters were significantly related $(p<0.05)$. The reduction in nitrotyrosine and iNOS immunoreactivity was correlated with the improvement in $\mathrm{FEV}_{1}(\mathrm{p}<0.05)$ and airway responsiveness to histamine $(p<0.01)$. None of the parameters was significantly changed by placebo administration. Conclusions: These results suggest that RNS may be involved in the reversible component of inflammation in COPD that is suppressed by steroids. Further studies using specific inhibitors for RNS are needed to clarify their effects on the long term progression of COPD.
\end{abstract}

$\Lambda^{1}$ lthough the pathogenesis of chronic obstructive pulmonary disease (COPD) has not yet been fully elucidated,' airway inflammation probably plays a key role. ${ }^{23}$ Reactive nitrogen species (RNS), which are formed from nitric oxide (NO) and superoxide anion, ${ }^{4}$ are upregulated during inflammatory conditions such as acute lung injury, bronchial asthma, ${ }^{67}$ and septic shock. ${ }^{8}$ Peroxynitrite activates matrix metalloproteinase (MMP), ${ }^{9}$ inactivates $\alpha_{1}$-antiproteinase, ${ }^{10}$ and enhances the production of the potent neutrophil chemoattractant interleukin 8 (IL-8). ${ }^{11}$ Another route of RNS formation is myeloperoxidase (MPO) dependent nitrite oxidation mechanisms and these pathways also cause cell dysfunction. ${ }^{12}$ RNS may therefore be involved in the pathophysiology of airways inflammation in patients with COPD.

RNS nitrate the tyrosine residues of protein to form nitrotyrosine which is a stable marker of RNS production in vivo. ${ }^{67}$ Plasma nitrotyrosine levels have been reported to be higher in smokers than in non-smokers, ${ }^{13}$ which suggests that increased RNS production may be caused by smoking, the most important aetiological factor in COPD. We recently reported that RNS production assessed by nitrotyrosine immunoreactivity in the airway inflammatory cells was upregulated in COPD, and the amount of RNS production was significantly correlated with the degree of airway obstruction. ${ }^{14}$ This supports the hypothesis that increased RNS production is a factor in the pathobiology of COPD.

Steroids have been reported to inhibit inducible NO synthase (iNOS) expression and to decrease RNS production in asthmatic airways. ${ }^{6}$ This study examined whether short term inhaled steroid treatment suppresses RNS production in the airways of patients with COPD and, if so, whether steroids modify pulmonary function in these patients by RNS suppression.

\section{METHODS}

Subjects

Eighteen patients aged 49-75 years with stable COPD who had been diagnosed according to the criteria of the American Thoracic Society ${ }^{15}$ participated in the study. The characteristics of the subjects are shown in table 1. Almost all subjects had the characteristics of pulmonary emphysema including increased lung volume, decreased lung transfer factor, and decreased lung static compliance. To exclude patients with asthma, subjects with one or more of the following features were excluded from the study: a history of perennial allergic rhinitis, positive allergen skin prick tests and RAST assay, a history of periodic wheezing, and an improvement in forced expiratory volume in l second $\left(\mathrm{FEV}_{1}\right)$ of more than $12 \%$ from the predicted values or an absolute increase of $200 \mathrm{ml}$ after inhalation of $200 \mu \mathrm{g}$ salbutamol. Smoking status was checked carefully by means of a questionnaire because cigarette smoke contains RNS which may cause nitrotyrosine formation in airways. All subjects were ex-smokers who had stopped smoking for at least 1 year before the study. None had had bronchial or respiratory tract infections in the month preceding the study. Patients were excluded if they had taken systemic glucocorticoids during the 2 months before the study or inhaled glucocorticoids in the month before the study. The study was conducted with the approval of the Tohoku University Committee on Clinical Investigation and informed written consent was obtained from the patients. 
Table 1 Characteristics of study subjects

\begin{tabular}{|c|c|c|c|c|c|c|c|c|c|c|}
\hline No. & Age & Sex & Smoking & VC (I) & $\mathrm{FEV}_{1}(\mathrm{I})$ & $\% \operatorname{TLC}(\%)$ & $\%$ TLCO (\%) & $\begin{array}{l}\mathrm{Cst} \\
\left(\mathrm{l} / \mathrm{cmH}_{2} \mathrm{O}\right)\end{array}$ & NO (ppb) & Medication \\
\hline \multicolumn{11}{|c|}{ Steroid treatment group } \\
\hline 1 & 49 & $M$ & Ex & 3.97 & 1.43 & 131 & 36.5 & 0.47 & 16 & $\mathrm{~T}, \mathrm{AC}$ \\
\hline 2 & 70 & $M$ & Ex & 1.53 & 0.68 & 143 & 35.0 & 0.33 & 10 & $T, A C, B$ \\
\hline 3 & 72 & $M$ & Ex & 1.66 & 0.79 & 123 & 26.2 & 0.36 & 13 & $\mathrm{~T}, \mathrm{AC}$ \\
\hline 4 & 53 & $M$ & Ex & 3.85 & 1.46 & 120 & 45.2 & 0.50 & 10 & $\mathrm{~T}$ \\
\hline 5 & 71 & $M$ & Ex & 2.88 & 0.85 & 124 & 36.9 & 0.34 & 15 & $T, A C, B$ \\
\hline 6 & 75 & $M$ & Ex & 2.79 & 0.69 & 112 & 45.5 & 0.32 & 14 & $\mathrm{~T}$ \\
\hline 7 & 71 & $M$ & Ex & 2.99 & 1.05 & 107 & 52.4 & 0.46 & 18 & $T, A C, B$ \\
\hline 8 & 69 & $M$ & Ex & 3.17 & 1.02 & 149 & 39.2 & 0.49 & 8 & $\mathrm{~T}, \mathrm{~B}$ \\
\hline 9 & 69 & $M$ & Ex & 2.33 & 1.22 & 120 & 51.7 & 0.31 & 9 & $\mathrm{~T}$ \\
\hline 10 & 64 & $M$ & Ex & 3.25 & 1.33 & N.D. & N.D. & 0.35 & 7 & $\mathrm{~T}, \mathrm{AC}$ \\
\hline 11 & 67 & $\mathrm{~F}$ & Ex & 2.50 & 1.45 & 109 & 53.0 & N.D. & 30 & $\mathrm{~T}$ \\
\hline 12 & 69 & $M$ & Ex & 3.23 & 1.07 & 123 & 60.3 & N.D. & 14 & $\mathrm{~T}, \mathrm{AC}$ \\
\hline Mean & 66.6 & & & 2.85 & 1.09 & 125 & 41.0 & 0.39 & 13.7 & \\
\hline SE & 2.4 & & & 0.23 & 0.09 & 4.2 & 3.2 & 0.03 & 1.9 & \\
\hline \multicolumn{11}{|c|}{ Placebo treatment group } \\
\hline 13 & 65 & $M$ & Ex & 2.49 & 0.66 & 146 & 45.2 & 0.45 & 26 & $T, A C, B$ \\
\hline 14 & 65 & $M$ & Ex & 4.24 & 1.97 & 122 & 40.4 & 0.32 & 5 & $T, A C, B$ \\
\hline 15 & 76 & $M$ & Ex & 2.54 & 1.75 & 124 & 46.5 & 0.33 & 11 & $\mathrm{~T}, \mathrm{AC}$ \\
\hline 16 & 65 & $\mathrm{~F}$ & Ex & 2.96 & 1.70 & 104 & 52.9 & 0.29 & 17 & $\mathrm{~T}, \mathrm{~B}$ \\
\hline 17 & 69 & $M$ & Ex & 3.35 & 1.09 & 131 & 38.4 & 0.42 & 11 & $T, A C, B$ \\
\hline 18 & 65 & $M$ & Ex & 2.99 & 1.35 & 130 & 28.9 & 0.46 & 5 & $T, A C, B$ \\
\hline Mean & 67.5 & & & 3.10 & 1.42 & 126 & 42.1 & 0.38 & 12.5 & \\
\hline SE & 2.0 & & & 0.29 & 0.22 & 6.1 & 3.7 & 0.03 & 3.6 & \\
\hline
\end{tabular}

$\mathrm{NO}=$ nitric oxide; $\mathrm{iNOS}=$ inducible $\mathrm{NO}$ synthase; $\mathrm{NT}=$ nitrotyrosine; $\mathrm{Ex}=\mathrm{ex}$-smoker; $\mathrm{ND}=$ not done; $\mathrm{T}=$ theophylline; $\mathrm{AC}=$ anticholinergic agents; $\mathrm{B}=\beta$ adrenoceptor agonists; $\mathrm{VC}=$ vital capacity; $\mathrm{FEV}_{1}=$ forced expiratory volume in 1 second; TLC=total lung capacity; $T L C O=$ carbon monoxide transfer factor; Cst=static compliance; $\mathrm{NO}=$ nitric oxide.

\section{Pulmonary function tests}

Pulmonary function was assessed with a dry rolling seal spirometer (Chestac 11, Chest Co, Tokyo, Japan) and both static compliance (Cst) and thoracic gas volume were measured using a constant volume, pressure compensated, whole body plethysmograph (2800J Autobox; Gould Electronics, Dayton, OH, USA). Carbon monoxide transfer factor (TLCO) was assessed with a total pulmonary function analyser (FUDAC-70; Fukuda Electronics Co, Tokyo, Japan).

\section{Measurement of exhaled NO}

A rapid response chemiluminescent analyser (280NOA; Sieverse Instruments Inc, Boulder, CO, USA) was used for the analysis of exhaled NO. Humidified standard medical grade compressed air $\left(21 \% \mathrm{O}_{2}\right.$ /balance $\mathrm{N}_{2}$, NO concentration $<\mathrm{lppb}$ ) was used as the inspired gas mixture. Two point calibrations were performed and the analyser sample flow rate was adjusted to $200 \mathrm{ml} / \mathrm{min}$. Exhaled $\mathrm{NO}$ was measured as previously described..$^{14}{ }^{16}$ Briefly, the subjects immediately inspired to total lung capacity (TLC) and exhaled. During the expiration they were asked to maintain a constant mouth pressure of $20 \mathrm{~cm} \mathrm{H}_{2} \mathrm{O}$ to close the vellum, thus excluding nasal NO, and a constant expiratory flow rate of $100 \mathrm{ml} / \mathrm{s}$. The exhaled NO values were defined as a plateau of at least 5 seconds during a constant flow rate. Repeated exhalations yielding three values of NO that varied by less than $10 \%$ were recorded.

\section{Airway responsiveness}

Airway responsiveness to histamine was measured according to the method of Chai and coworkers ${ }^{17}$ with a DeVilbiss 646 nebuliser (Somerset, Pennsylvania, USA) controlled by a dosimeter (FDC 88; Mediprom, Paris, France). Briefly, after measurement of baseline $\mathrm{FEV}_{1}$, the subjects inspired five breaths of a histamine aerosol at a concentration of $0.156 \mathrm{mg} /$ $\mathrm{ml}$ from functional residual capacity (FRC) to TLC. If the FEV was decreased by less than $20 \%$, the provocation test was continued by doubling the dose every 3 minutes until a decrease in $\mathrm{FEV}_{1}$ of $20 \%$ from baseline was achieved. The percentage fall in FEV from baseline was then plotted against the cumulative histamine dose. The provocative dose of histamine producing a $20 \%$ fall in $\mathrm{FEV}_{1}\left(\mathrm{PD}_{20}\right)$ was obtained from each doseresponse curve.

\section{Sputum induction and processing}

Sputum was induced and processed as described in previous studies. ${ }^{14} 18$ All subjects inhaled $200 \mu \mathrm{g}$ fenoterol to avoid hypertonic saline induced bronchoconstriction. Fifteen minutes after fenoterol, $4 \%$ hypertonic saline was inhaled using an ultrasonic nebuliser (MU-32; Sharp Co Ltd, Osaka, Japan). The nebuliser generated particles with a mean mass median diameter of $5.4 \mu \mathrm{m}$ at an output of $2.2 \mathrm{ml} / \mathrm{min}$. Saliva contamination was eliminated by visual inspection and examination with an inverted microscope. Hypertonic saline inhalation was performed for 15-30 minutes until the sputum volume was approximately $1 \mathrm{ml}$. The sputum sample was immediately treated with 4 times the volume of Sputasol (Oxoid Ltd, Basingstoke, Hampshire, UK) to dissociate the sulfide bonds of the mucus. The mixture was vortexed for 15 seconds and gently aspirated in and out of a Pasteur pipette to ensure mixing. The sample was rocked for 15 minutes and phosphate buffered saline (PBS) was added to stop the effect of Sputasol. After centrifugation at $790 \mathrm{~g}$ for 10 minutes the cell pellet was resuspended in a half volume of sputum with PBS and the total leucocyte count was obtained using a haemocytometer. Cell viability was determined by the trypan blue exclusion method. The total and absolute numbers of cells $/ \mathrm{ml}$ processed sputum were calculated. $100 \mu \mathrm{l}$ of the cell suspension adjusted to $1.0 \times 10^{6} / \mathrm{ml}$ were placed in a Shandon III cytocentrifuge (Shandon Southern Instruments, Sewickley, PA, USA), centrifuged at $30 \mathrm{~g}$ for 5 minutes, and four portions of the preparation were obtained for each sample. The preparation was stained with Hansel's stain (Torii Pharmaceutical, Tokyo, Japan) to assess the cell differential counts. ${ }^{14}$

\section{Immunocytostaining}

The preparation was fixed in $4 \%$ paraformaldehyde fixative solution for 30 minutes. Endogenous peroxidase activity was 

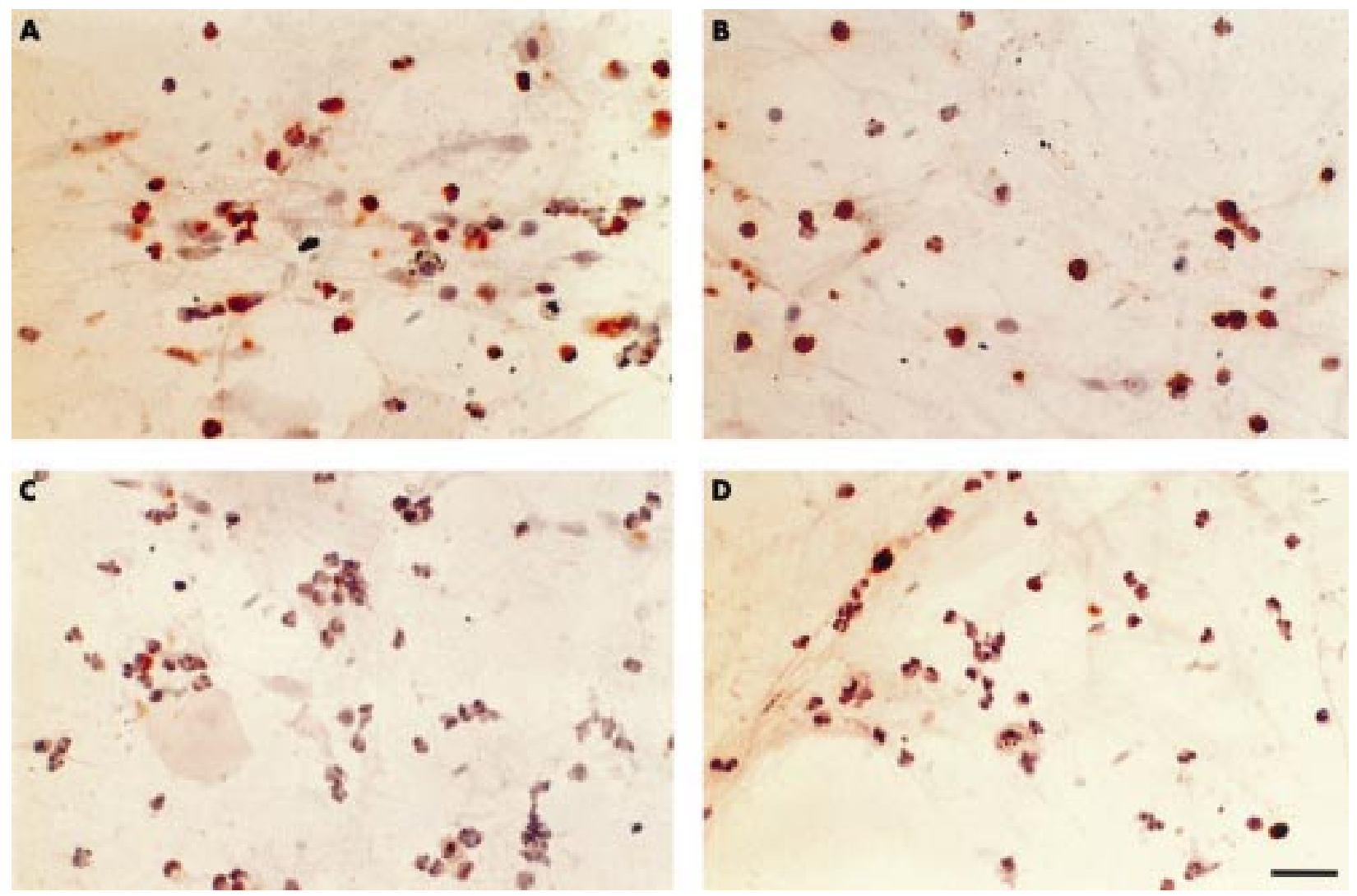

Figure 1 Immunohistochemical localisation of inducible nitric oxide synthase (iNOS) and nitrotyrosine in induced sputum cells from patients with chronic obstructive pulmonary disease (COPD). iNOS (A) and nitrotyrosine (B) immunopositive staining was observed mainly in macrophages and neutrophils before treatment with inhaled steroids. Significant reductions in both iNOS (C) and nitrotyrosine (D) immunopositive cells were observed after steroid treatment. Scale bar $=30 \mu \mathrm{m}$.

reduced by incubation in 3\% hydrogen peroxide in $100 \%$ methanol for 5 minutes at room temperature. After washing in PBS the preparations were incubated with primary antibody (anti-nitrotyrosine rabbit polyclonal IgG, 1:100 dilution; Upstate Biotechnology, Lake Placid, NY, USA $)^{514}$ or antiiNOS rabbit antisera (1:200 dilution; Wako Pure Chemical Industries, Osaka, Japan $)^{14} 19$ for 12 hours at $4^{\circ} \mathrm{C}$. In order to reduce non-specific binding of the antibody the preparations were preincubated with $4 \%$ skimmed milk in PBS containing $0.3 \%$ Triton- $X$ for 30 minutes and then incubated with $10 \%$ inactivated normal goat serum for 30 minutes at room temperature. The immunoreactions were visualised by the indirect immunoperoxidase method using Envision polymer reagent which is anti-rabbit IgG from goat conjugated with peroxidase labelled dextran (Dako Japan Ltd, Kyoto, Japan) for 1 hour at room temperature. The diaminobenzidine reaction was performed, followed by counterstaining with Hansel's stain. Slides were coded and immunopositive cells were counted by two blinded investigators. In all cases the mean of the two values was registered.

\section{Study protocol}

On the first day patients were randomised into placebo or steroid treatment groups. After NO and FEV ${ }_{1}$ measurements, sputum induction was carried out. The histamine inhalation challenge test was performed on a separate day. After baseline value assessment, inhaled steroid ( $800 \mu \mathrm{g}$ beclomethasone/ day) was administered to 12 patients for 4 weeks and six patients received placebo treatment for the same period. After each 4 week treatment period the same procedure was repeated. All bronchodilator treatments were stopped $\geqslant 24$ hours before the examination.

\section{Statistical analysis}

Data are expressed as mean (SE). Comparison of outcomes between the placebo and steroid treatment groups was performed using the Mann-Whitney U test and Wilcoxon's rank test was used to compare the effect of treatment on total and differential cell counts and pulmonary function. Pearson's correlation analysis was used to assess the correlation between changes in RNS markers and those in lung function and airway hyperresponsiveness. $p$ values of $<0.05$ were considered significant.

\section{RESULTS}

Before steroid treatment abundant iNOS and nitrotyrosine immunoreactivity was seen in the inflammatory cells of the induced sputum from subjects in both the steroid treatment (fig $1 \mathrm{~A}$ and $\mathrm{B})$ and placebo groups. Both the iNOS $(\mathrm{n}=18$, $r=-0.50, \mathrm{p}<0.05)$ and nitrotyrosine $(\mathrm{n}=18, r=-0.68, \mathrm{p}<0.01)$ positive cell counts in the sputum were significantly correlated with $\% \mathrm{FEV}_{1}$ but not with the other pulmonary function parameters. The exhaled NO concentration was not significantly correlated with any pulmonary function parameter.

When iNOS and nitrotyrosine immunoreactivity in sputum cells was compared after treatment there was no significant difference between the placebo and steroid groups, nor was there any difference in lung function and airway responsiveness between the groups after treatment. However, when the pretreatment values were compared with the values after treatment, the eosinophil count in the sputum of the group treated with inhaled steroids was slightly but significantly reduced (from $4.7(2.2) \times 10^{4} / \mathrm{ml}$ to $2.5(1.5) \times 10^{4} / \mathrm{ml}, \mathrm{p}<0.05$; table 2 ). In contrast, the total cell, macrophage, neutrophil, and lymphocyte cell counts were not affected by steroid treatment. Placebo treatment caused no change in the cell counts 
Table 2 Cell differential counts in sputum of patients treated with steroids or placebo

\begin{tabular}{|c|c|c|c|c|c|}
\hline & \multirow{2}{*}{$\begin{array}{l}\text { Total cell } \\
\text { counts }\end{array}$} & \multicolumn{4}{|c|}{ Cellular differential counts $\left(\times 10^{4} / \mathrm{ml}\right)$} \\
\hline & & Macrophages & Neutrophils & Eosinophils & Lymphocytes \\
\hline \multicolumn{6}{|c|}{ Steroid treatment group } \\
\hline Before & $147(25.8)$ & $44.8(9.8)$ & $90.3(19.0)$ & $4.7(2.2)$ & $6.9(1.7)$ \\
\hline After & $148(24.3)$ & $55.4(15.9)$ & $84.7(15.4)$ & $2.5(1.5)^{*}$ & $9.9(3.5)$ \\
\hline \multicolumn{6}{|c|}{ Placebo treatment group } \\
\hline Before & $203(98.5)$ & $66.3(35.0)$ & $128(64.1)$ & $4.2(3.4)$ & $4.4(0.9)$ \\
\hline After & $158(75.8)$ & $36.1(12.1)$ & 111 (62.0) & $4.4(3.0)$ & $6.9(2.4)$ \\
\hline
\end{tabular}

\begin{tabular}{|c|c|c|c|c|c|c|c|c|c|c|}
\hline \multirow[b]{2}{*}{ No. } & \multicolumn{2}{|c|}{$\mathrm{FEV}_{1}$ (I) } & \multicolumn{2}{|c|}{$\mathrm{PD}_{20}(\mu \mathrm{mol})$} & \multicolumn{2}{|c|}{ NO (ppb) } & \multicolumn{2}{|c|}{$\begin{array}{l}\text { iNOS positive cell count } \\
\left(\times 10^{4} / \mathrm{ml}\right)\end{array}$} & \multicolumn{2}{|c|}{$\begin{array}{l}\text { NT positive cell count } \\
\left(\times 10^{4} / \mathrm{ml}\right)\end{array}$} \\
\hline & Pre & Post & Pre & Post & Pre & Post & Pre & Post & Pre & Post \\
\hline \multicolumn{11}{|c|}{ Steroid treatment group } \\
\hline 1 & 1.43 & 1.69 & 0.027 & 0.055 & 16 & 33 & 43.1 & 9.3 & 55.2 & 27.2 \\
\hline 2 & 0.68 & 0.69 & 0.020 & 0.021 & 10 & 8 & 75.0 & 71.3 & 160.0 & 141.0 \\
\hline 3 & 0.79 & 0.97 & 0.068 & 0.224 & 13 & 10 & 41.3 & 21.3 & 45.1 & 24.6 \\
\hline 4 & 1.46 & 1.53 & 0.255 & 0.228 & 10 & 8 & 92.0 & 70.0 & 72.9 & 71.1 \\
\hline 5 & 0.85 & 0.93 & 0.082 & 0.140 & 15 & 10 & 68.4 & 36.5 & 103.0 & 66.0 \\
\hline 6 & 0.69 & 0.79 & 0.039 & 0.106 & 14 & 17 & 87.8 & 55.3 & 95.0 & 46.1 \\
\hline 7 & 1.05 & 1.18 & 0.175 & 0.553 & 18 & 10 & 77.0 & 24.2 & 146.0 & 40.7 \\
\hline 8 & 1.02 & 1.24 & 0.139 & 0.230 & 8 & 8 & 34.4 & 13.2 & 28.3 & 24.4 \\
\hline 9 & 1.22 & 1.01 & 0.164 & 0.157 & 9 & 10 & 3.1 & 3.4 & 15.1 & 18.2 \\
\hline 10 & 1.33 & 1.40 & 0.010 & 0.028 & 7 & 8 & 53.3 & 39.2 & 75.9 & 27.3 \\
\hline 11 & 1.45 & 1.50 & 0.150 & 0.230 & 30 & 31 & 21.8 & 18.4 & 22.7 & 21.4 \\
\hline 12 & 1.07 & 1.26 & 0.040 & 0.150 & 14 & 2 & 55.9 & 26.4 & 102.0 & 49.5 \\
\hline Mean & 1.09 & $1.18^{*}$ & 0.097 & $0.177^{*}$ & 13.7 & 12.9 & 54.4 & $32.4^{* *}$ & 76.8 & $46.5^{* *}$ \\
\hline SE & 0.09 & 0.09 & 0.02 & 0.04 & 1.9 & 2.9 & 8.2 & 6.9 & 14.1 & 10.4 \\
\hline \multicolumn{11}{|c|}{ Placebo treatment group } \\
\hline 13 & 0.66 & 0.68 & 0.025 & 0.020 & 26 & 29 & 95.8 & 74.0 & 160.0 & 82.3 \\
\hline 14 & 1.97 & 2.04 & 0.124 & 0.137 & 5 & 7 & 94.8 & 70.1 & 79.0 & 54.7 \\
\hline 15 & 1.75 & 1.81 & 0.178 & 0.236 & 11 & 12 & 48.3 & 54.4 & 47.2 & 57.8 \\
\hline 16 & 1.70 & 1.71 & 0.198 & 0.185 & 17 & 16 & 17.3 & 22.0 & 23.3 & 37.0 \\
\hline 17 & 1.09 & 1.02 & 0.076 & 0.068 & 11 & 11 & 39.1 & 51.1 & 45.9 & 67.0 \\
\hline 18 & 1.35 & 1.35 & 0.112 & 0.125 & 5 & 5 & 67.6 & 35.3 & 64.8 & 45.5 \\
\hline Mean & 1.42 & 1.44 & 0.119 & 0.129 & 12.5 & 13.3 & 60.5 & 51.2 & 70.0 & 57.4 \\
\hline SE & 0.22 & 0.23 & 0.03 & 0.03 & 3.6 & 3.8 & 14.1 & 8.9 & 21.4 & 7.1 \\
\hline
\end{tabular}

$\mathrm{FEV} \mathrm{V}_{1}=$ forced expiratory volume in 1 second; $\mathrm{PD}_{20}=$ dose of histamine provoking a fall in $\mathrm{FEV}$ of $20 \%$ or more; pre and post=values before and after steroid (or placebo) treatment.

${ }^{*} p<0.05,{ }^{*} p<0.01$ compared with values before steroid treatment.

or cell differentiation (table 2). Treatment with steroids significantly reduced the immunoreactivity of iNOS in total cells (from $55.0(8.3) \times 10^{4} / \mathrm{ml}$ to $28.1(4.9) \times 10^{4} / \mathrm{ml}, \mathrm{p}<0.01$ ), macrophages (from $25.3(5.0) \times 10^{4} / \mathrm{ml}$ to $12.2(2.6) \times 10^{4} / \mathrm{ml}$, $\mathrm{p}<0.01$ ), and neutrophils (from $28.6(6.5) \times 10^{4} / \mathrm{ml}$ to 15.8 $\left.(4.0) \times 10^{4} / \mathrm{ml}, \mathrm{p}<0.01\right)$. Steroid treatment also reduced the immunoreactivity of nitrotyrosine in total cells (from 78.3 $(14.0) \times 10^{4} / \mathrm{ml}$ to $\left.44.5(10.9) \times 10^{4} / \mathrm{ml}, \mathrm{p}<0.01\right)$, macrophages (from $29.9(6.8) \times 10^{4} / \mathrm{ml}$ to $\left.18.2(5.2) \times 10^{4} / \mathrm{ml}, \mathrm{p}<0.05\right)$, and neutrophils (from $47.6(10.6) \times 10^{4} / \mathrm{ml}$ to $26.1(7.2) \times 10^{4} / \mathrm{ml}$, $\mathrm{p}<0.01$; table 3 , fig 2 ). The magnitude of the steroid mediated reduction in iNOS and nitrotyrosine immunoreactive cell counts was positively correlated $(r=0.69, \mathrm{p}<0.05)$ in the steroid treated group (fig 3 ).

The magnitude of the reduction in iNOS immunopositive cell counts in the steroid treatment group was significantly related to the change in $\mathrm{FEV}_{1}(r=-0.82, \mathrm{p}<0.01)$ and $\mathrm{PD}_{20}$ $(r=-0.58, \mathrm{p}<0.05$; fig 4$)$. The changes in nitrotyrosine immunoreactive cell counts in steroid treated patients were also significantly correlated with the change in $\mathrm{FEV}_{1}(r=-0.62$, $\mathrm{p}<0.05)$ and $\mathrm{PD}_{20}(r=-0.85, \mathrm{p}<0.01$; fig 5$)$. Furthermore, the steroid induced changes in $\mathrm{FEV}_{1}$ and $\mathrm{PD}_{20}$ were positively correlated $(r=0.60, \mathrm{p}<0.05)$ in the steroid treatment group (fig 6).

In the steroid treatment group the exhaled NO levels were slightly reduced by steroid treatment but the changes were not significant (table 3 ).

In the placebo group iNOS and nitrotyrosine immunopositive cell counts, exhaled NO levels, $\mathrm{FEV}_{1}$, and airway responsiveness to histamine were not affected significantly changed (table 3 ).

\section{DISCUSSION}

We have shown that treatment with inhaled steroids for 4 weeks significantly reduced RNS production in proportion to changes in lung function and airway responsiveness in subjects with COPD.

Oxidative stress has been reported to be involved in the inflammatory process in the airways of patients with COPD. ${ }^{20}{ }^{21}$ Among the molecules which cause oxidative stress, the RNS seem to be important because these mediators cause cell injury, ${ }^{4}$ activation of metalloproteinases, ${ }^{9}$ inactivation of 

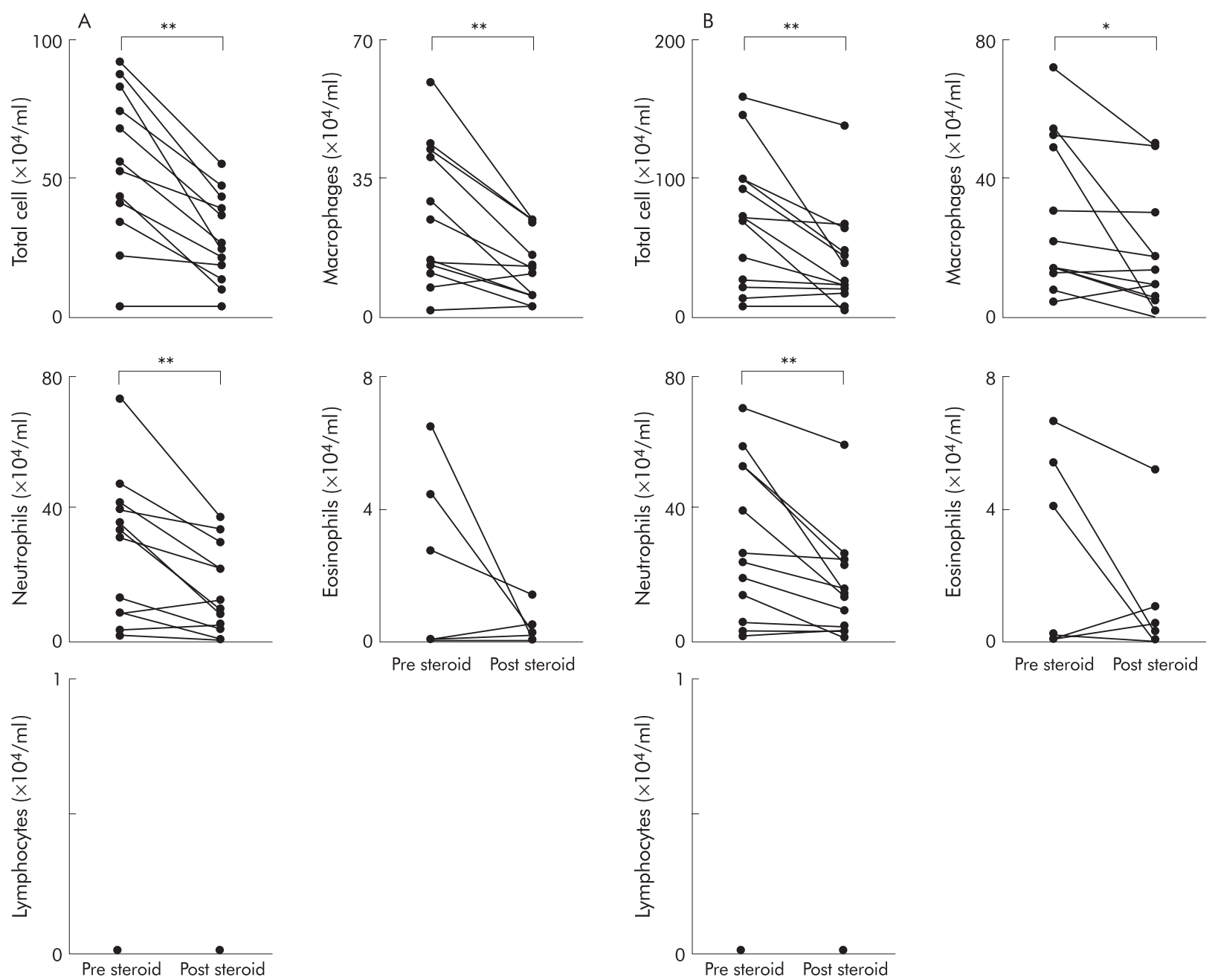

Figure 2 Total and differential cell counts in (A) iNOS and (B) nitrotyrosine immunopositive sputum samples before and after steroid treatment. ${ }^{*} p<0.05,{ }^{* *} p<0.01$ compared with values before steroid treatment.

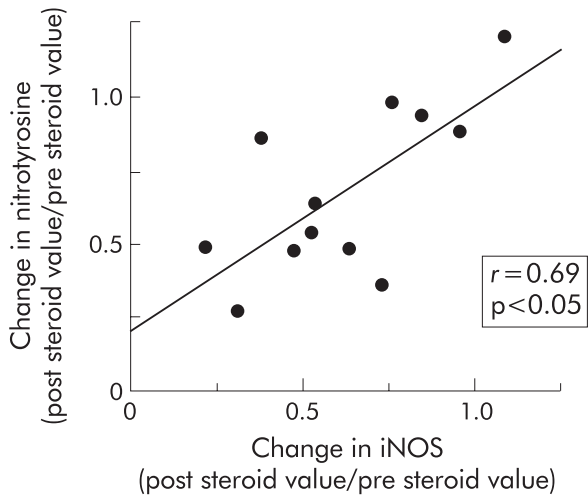

Figure 3 Relationship between steroid induced reduction in nitrotyrosine and iNOS immunopositive cell counts.

$\alpha_{1}$-antiproteinase, ${ }^{10}$ and enhancement of IL-8 production, ${ }^{11}$ all of which have been reported to be involved in the pathobiology of COPD. ${ }^{2}$ Furthermore, nitrotyrosine itself causes microtubular dysfunction in alveolar type II epithelial cells. ${ }^{22}$ We have recently reported that RNS are excessively produced in the airways of patients with COPD and their levels are significantly correlated with the degree of changes in airway obstruction..$^{14}$ In the present study the number of nitrotyrosine immunoreactive inflammatory cells was significantly corre- lated with the baseline $\mathrm{FEV}_{1}$ values, which is compatible with the results of our previous study.

Patients with COPD were randomised into two groups, but there was an imbalance in the numbers in the placebo and steroid treatment groups. Because RNS markers and lung function were thought to be unchanged following placebo treatment, two thirds of the patients were randomised into the steroid treatment group. There was therefore no statistically significant difference in any post-treatment values between the two groups because of the low study power. However, the aim of this study was not to show the usefulness of steroid treatment for COPD, but to assess the relationship between changes in RNS markers and those in lung function following steroid treatment.

Steroids are the most powerful agents for suppressing airway inflammation in bronchial asthma but they have been reported to be less effective in COPD. ${ }^{3}$ In the present study steroid inhalation slightly but significantly improved $\mathrm{FEV}_{1}$ (from $1.09(0.09) \mathrm{l}$ to $1.18(0.09) \mathrm{l}, \mathrm{p}<0.05)$ and $\mathrm{PD}_{20}$ (from 0.097 (0.02) $\mu \mathrm{mol}$ to $0.177 \quad(0.02) \mu \mathrm{mol}, \mathrm{p}<0.05)$. These results suggest that steroids suppress airway inflammation in COPD and that this may be due to nitrosative stress, because the changes in $\mathrm{FEV}_{1}$ and $\mathrm{PD}_{20}$ induced by steroid treatment were significantly correlated with changes in nitrotyrosine immunoreactive cell numbers.

Steroids have been reported to suppress eosinophil infiltration into the airways in patients with COPD. ${ }^{23}$ The number of eosinophils in the sputum was significantly reduced by steroid 
A

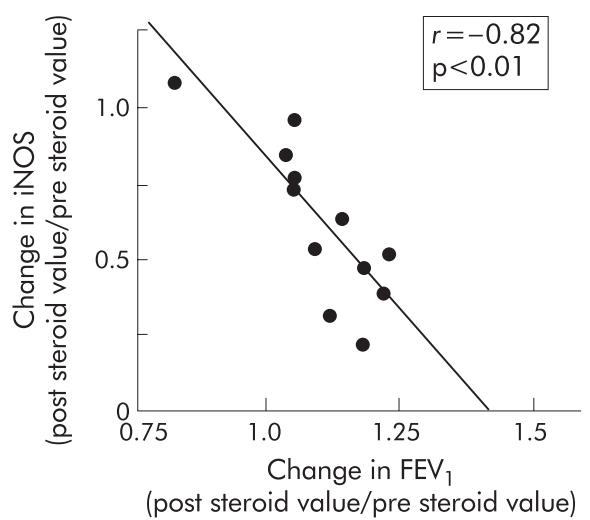

B

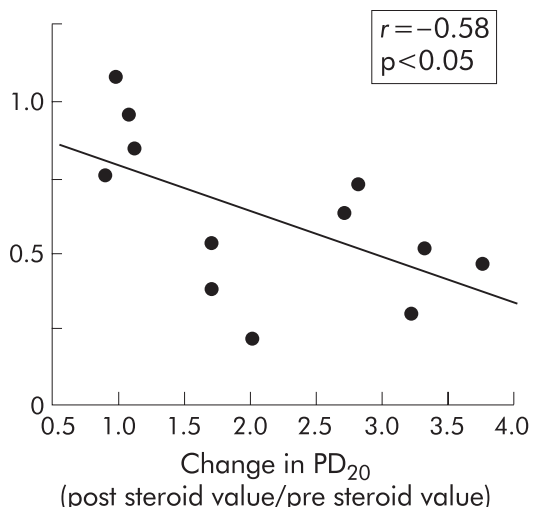

Figure 4 Relationship between steroid induced reduction in iNOS immunopositive cell counts and changes in (A) forced expiratory volume in 1 second $\left(\mathrm{FEV}_{1}\right)$ and $(\mathrm{B})$ dose of histamine provoking a $20 \%$ fall in $\mathrm{FEV}_{1}\left(\mathrm{PD}_{20}\right)$.

A

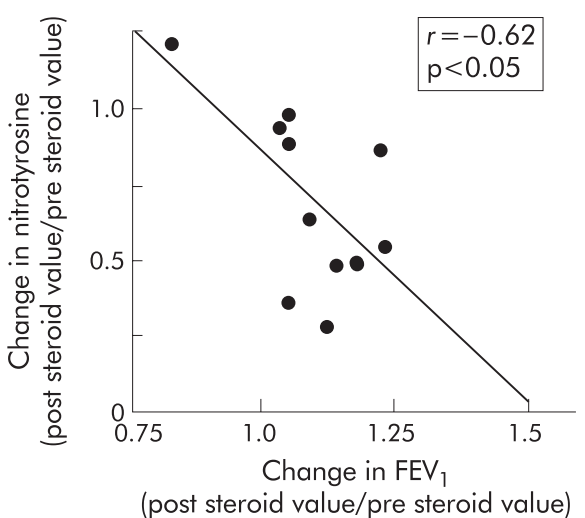

B

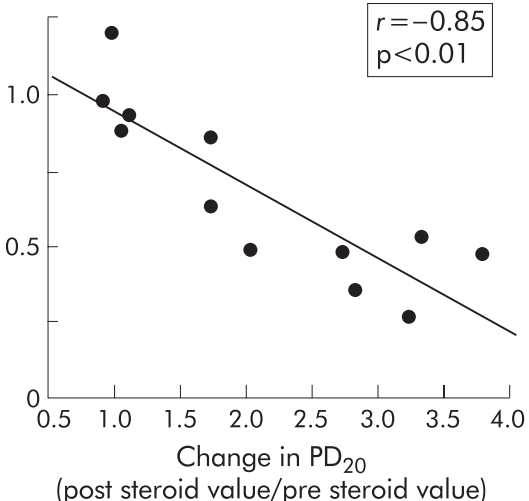

Figure 5 Relationship between steroid induced reduction in nitrotyrosine immunopositive cell counts and changes in (A) forced expiratory volume in 1 second $\left(\mathrm{FEV}_{1}\right)$ and $(\mathrm{B})$ dose of histamine provoking a $20 \%$ fall in $\mathrm{FEV}_{1}\left(\mathrm{PD}_{20}\right)$.

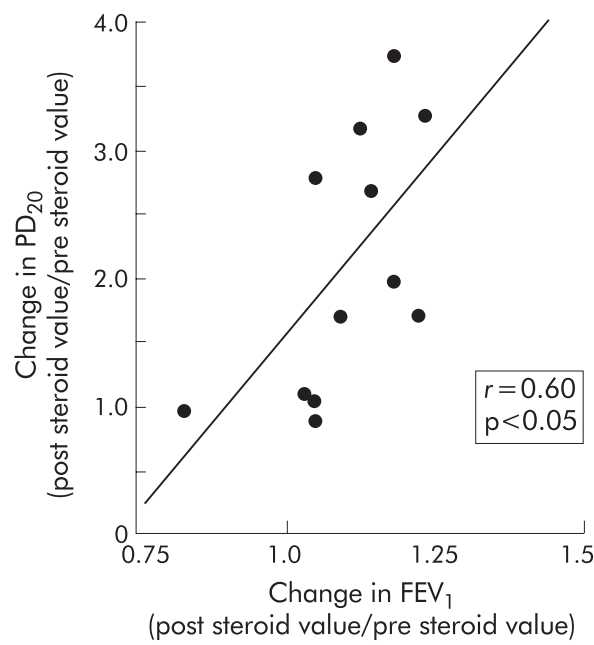

Figure 6 Relationship between steroid induced changes in forced expiratory volume in 1 second $\left(\mathrm{FEV}_{1}\right)$ and dose of histamine provoking a $20 \%$ fall in $\mathrm{FEV}_{1}\left(\mathrm{PD}_{20}\right)$.

treatment without any change in the total number of inflammatory cells or in the balance of any other inflammatory cells (table 2). This result is compatible with that of previous reports. Moreover, both iNOS and nitrotyrosine immunopositive eosinophil numbers tended to be decreased, although not significantly. Since there were few iNOS and nitrotyrosine immunopositive eosinophils before steroid treatment, the difference was not statistically significant although the number of eosinophils was significantly reduced by steroids.

Steroids have a number of anti-inflammatory actions including inhibition of iNOS expression. ${ }^{24}$ In the present study, nitrotyrosine immunoreactivity in airway inflammatory cells, which is a footprint of RNS production, was decreased by steroid treatment in proportion to the degree of iNOS reduction, which suggests that iNOS suppression is the primary mechanism for RNS inhibition by steroids. In asthmatic subjects an inhaled steroid induced improvement in airway calibre and responsiveness and a reduction in RNS has been reported. ${ }^{6}$ We have shown that this is also the case in patients with COPD, but to a lesser extent.

The large amount of NO derived from iNOS is likely to have a pivotal role in the airway inflammatory process. An increase in the level of exhaled NO and its participation in the pathobiology of asthmatic airway inflammation has been reported. ${ }^{6}{ }^{1425}$ In contrast, in patients with COPD the level of exhaled NO is the same or only slightly increased compared with healthy subjects. ${ }^{14} 26$ In the present study the baseline exhaled NO levels were 13.7 (1.9) ppb, which were similar to those of the healthy subjects in our previous report. ${ }^{14}$ However, in patients with COPD the iNOS expression in the airway inflammatory cells was almost the same as that of the asthmatic subjects in our previous ${ }^{14}$ and present study. Abundant nitrotyrosine formation was also observed in both studies. The formation of nitrotyrosine depends on the oxidation of NO. NO reacts with superoxide anion to yield the powerful 
oxidant peroxynitrite ${ }^{4}$ which nitrates tyrosine residues resulting in nitrotyrosine formation. An alternative pathway of nitrotyrosine formation via NO involves mechanisms dependent on myeloperoxidase ${ }^{12}$ or related peroxidases. ${ }^{21}{ }^{27}$ It is therefore possible that NO produced via iNOS is, at least in part, consumed by its reaction with superoxide anion and/or by peroxidase dependent nitrite oxidation in COPD airways. ${ }^{14}$

Airway hyperresponsiveness is a fundamental feature of patients with asthma and COPD. It has been reported to be more important in asthmatic patients than in those with COPD, but in COPD it has been shown that airway hyperresponsiveness is correlated with the severity of symptoms ${ }^{28}$ and progression of the disease. ${ }^{29}$ The improvement in airway hyperresponsiveness might therefore be beneficial for the care of COPD patients. In the present study treatment with inhaled steroids slightly but significantly improved airway hyperresponsiveness. Airway responsiveness to histamine was also improved by steroid treatment in proportion to the degree of RNS reduction. The airway hyperresponsiveness observed in COPD has been reported to depend on the airway calibre. ${ }^{30}$ In the present study the steroid induced changes in $\mathrm{FEV}_{1}$ and airway responsiveness were significantly correlated. Taken together, the change in airway responsiveness by steroid treatment was possibly related to the change in baseline airway calibre.

The progressive airflow limitation observed in COPD seems to be due to airway inflammatory mechanisms. ${ }^{31}$ At the present time smoking cessation is the only known intervention that prevents the long term progression of the airway obstructive changes in COPD. ${ }^{31}$ Drug treatments including steroids fail to suppress the long term decline in $\mathrm{FEV}_{1}$ in COPD. ${ }^{14}$ We have shown that short term steroid inhalation changed the airway calibre in proportion to the reduction in RNS production. This suggests that specific inhibition of RNS production might be useful for controlling the inflammatory changes in the airways of patients with COPD. Further study of the long term effects of a specific RNS modulator is needed.

In summary, treatment with inhaled steroids significantly reduces RNS production in patients with COPD. The degree of reduction of RNS is significantly correlated with changes in pulmonary function such as $\mathrm{FEV}_{1}$ and airway responsiveness, which suggests that RNS mediated inflammatory mechanisms are, at least in part, involved in the airway obstructive process in COPD. The development of specific inhibitors or scavengers for RNS and an assessment of their effects on long term COPD progression is needed.

\section{ACKNOWLEDGEMENT}

The authors thank Mr Brent Bell for reading the manuscript.

\section{Authors' affiliations}

H Sugiura, M Ichinose, S Yamagata, A Koarai, K Shirato, T Hattori, Division of Respiratory and Infectious Diseases, Tohoku University Graduate School of Medicine, Sendai, Japan

Supported by Grant-in-Aid for Science Research (B) 12470132 from the Ministry of Education, Science, Sports, and Culture of Japan.

\section{REFERENCES}

1 American Thoracic Society. Standards for the diagnosis and care of patients with chronic obstructive pulmonary disease. Am J Respir Crit Care Med 1995;152: S77-120.

2 Barnes PJ. Mechanisms in COPD: differences from asthma. Chest 2000;1 17:10-14S

3 Barnes PJ. New therapies for chronic obstructive pulmonary disease. Thorax 1998:53:137-47.

4 Beckman JS, Beckman TW, Chen J, et al. Apparent hydroxyl radical production by peroxynitrite: implications for endothelial injury from nitric oxide and superoxide. Proc Natl Acad Sci USA 1990;87:1620-4.
5 Kooy NW, Royall JA, Ye YZ, et al. Evidence for in vivo peroxynitrite production in human acute lung injury. Am J Respir Crit Care Med 1995; 151:1250-4.

6 Saleh D, Ernst P, Lim S, et al. Increased formation of the potent oxidant peroxynitrite in the airways of asthmatic patients is associated with induction of nitric oxide synthase: effect of inhaled glucocorticoid. FASEB J 1998;12:929-37.

7 Sugiura $\mathbf{H}$, Ichinose $M$, Oyake $T$, et al. Role of peroxynitrite in airway microvascular hyperpermeability during late allergic phase in guinea pigs. Am J Respir Crit Care Med 1999;160:663-71.

8 Haddad IY, Pataki G, Hu P, et al. Quantification of nitrotyrosine levels in lung sections of patients and animals with acute lung injury. J Clin Invest 1994;94:2407-13.

9 Okamoto T, Akaike T, Nagano T, et al. Activation of human neutrophil procollagenase by nitrogen dioxide and peroxynitrite: a novel mechanism for procollagenase activation involving nitric oxide. Arch Biochem Biophys 1997;342:261-74.

10 Whiteman M, Szabo C, Halliwell B. Modulation of peroxynitrite- and hypochlorous acid-induced inactivation of $\alpha 1$-antiproteinase by mercaptoethylguanidine. Br J Pharmacol 1999;126:1646-52.

11 Filep JG, Beauchamp M, Baron C, et al. Peroxynitrite mediates IL-8 gene expression and production in lipopolysaccharide-stimulated human whole blood. J Immunol 1998;161:5656-62.

12 Eiserich JP, Hristova M, Cross CE, et al. Formation of nitric oxide-derived inflammatory oxidants by myeloperoxidase in neutrophils. Nature 1998;391:393-7.

13 Petruzzelli S, Puntoni R, Mimotti $\mathrm{P}$, et al. Plasma 3-nitrotyrosine in cigarette smokers. Am J Respir Crit Care Med 1997;156:1902-7.

14 Ichinose M, Sugiura H, Yamagata S, et al. Increase in reactive nitrogen species production in chronic obstructive pulmonary disease airways. Am J Respir Crit Care Med 2000;162:701-6.

15 American Thoracic Society. Lung function testing: selection of reference values and interpretative strategies. Am Rev Respir Dis 1995; 144:1202-18.

16 Silkoff PE, McClean PA, Slutsky AS, et al. Marked flow-dependence of exhaled nitric oxide using a new technique to exclude nasal nitric oxide. Am J Respir Crit Care Med 1997;155:260-7.

17 Chai H, Farr RS, Froehlich LA, et al. Standardization of bronchial inhalation challenge procedures. J Allergy Clin Immunol 1975;56:323-7.

18 Pizzichini E, Pizzichini MMM, Efthimiadis A, et al. Indicies of airway inflammation in induced sputum: reproducibility and validity of cell and fluid-phase measurements. Am J Respir Crit Care Med 1996;154:308-17.

19 Hamid Q, Springall DR, Riveros-Moreno V, et al. Induction of nitric oxide synthase in asthma. Lancet 1993;342:1510-3.

20 John ER, Bast A, Lankhorst I, and the Oxidative Stress Study Group. Oxidative stress in chronic obstructive pulmonary disease. Am J Respir Crit Care Med 1997;156:341-57.

21 van der Villet A, Eiserich JP, Shigenaga MK, et al. Reactive nitrogen species and tyrosine nitration in the respiratory tract. Am J Respir Crit Care Med 1999;160:1-9

22 Eiserich JP, Estevez AG, Bamberg TV, et al. Microtubule dysfunction by posttranslational nitrotyrosination of a-tubulin: a nitric oxide-dependent mechanism of cellular injury. Proc Natl Acad Sci USA 1999;96:6365-70

23 Brightling CE, Monteiro W, Ward R, et al. Sputum eosinophilia and short-term response to prednisolone in chronic obstructive pulmonary disease: a randomized controlled trial. Lancet 2000:356:1480-5.

24 Radomski MW, Palmer RM, Moncada S. Glucocorticoid inhibit the expression of an inducible, but not the constitutive nitric oxide synthase in vascular endothelial cells. Proc Natl Acad Sci USA 1990;87:10043-9.

25 Kharitonov SA, Yates D, Robbins RA, et al. Increased nitric oxide in exhaled air of asthmatic patients. Lancet 1994;343:133-5.

26 Maziak W, Loukides S, Culpitt S, et al. Exhaled nitric oxide in chronic obstructive pulmonary disease. Am J Respir Crit Care Med 1998;157:998-1002

27 Wu W, Chen Y, Hasen SL. Eosinophil peroxidase nitrates protein tyrosyl residues. Implication for oxidative damage by nitrating intermediates in eosinophilic inflammatory disorders. J Biol Chem 1999;274:25933-44.

28 Brand PLP, Postma DS, Kerstjens HAM, et al, the Dutch CNSLD Study Group. Relationship of airway hyperresponsiveness to respiratory symptoms and diurnal peak flow variation in patients with obstructive lung disease. Am Rev Respir Dis 1991;143:916-21.

29 Tashkin DP, Altose MD, Connett JE, et al, for the Lung Health Study Group. Methacholine reactivity predicts changes in lung function over time in smokers with early chronic obstructive pulmonary disease. Am J Respir Crit Care Med 1996;153:1802-11.

30 Verma VK, Cockcroft DW. Airway responsiveness to inhaled histamine in chronic obstructive airways disease: chronic bronchitis vs emphysema. Chest 1988;94:457-61

31 Pauwels RA, Lofdahl CG, Laitinen LA et al Long-term treatment with inhaled budesonide in persons with mild chronic obstructive pulmonary disease who continue smoking. European Respiratory Society Study on Chronic Obstructive Pulmonary Disease. N Engl J Med 1999;340: 1948-53. 